\title{
Sharpening the Theoretical Principles for Responding to Environmental Conflicts: Possible Legal Recommendations for Promoting the Judicial Activism in the Issues Relating to Sustainable Development in Sri Lanka
}

\author{
G.I.D.I. Udani \\ Department of Private and Comparative Law, Faculty of Law, University of Colombo, \\ Sri Lanka \\ udanigammanpila@yahoo.com
}

\begin{abstract}
The inherent value of the principle of sustainable development is predicated on the practical implementation, which extends beyond its normative character. Despite the fact that, environmental soft-law instruments which enriched the values of sustainable development have imposed specific obligations on state parties for pursing their national commitments, the task of adopting international accords into domestic enforcements still remains in an unsatisfactory position in the eyes of the law. In Sri Lanka, although a wide range of legislative enactments and national strategies have been formulated concerning the sustainable development, the existing framework has failed to eliminate the major confronted challenges on sustainability: such as illegal mining, illegal exporting of endangered species, environmental issues related with major development projects, deforestation for human settlements, unauthorised capturing and illegal possessing of wildlife, impact of micro hydroelectric power plants on ecosystems, conversion of paddy lands for constructions. As per the findings of the study, it is obvious that, the legal inadequacies embodied with this area; especially, non-recognition of the right to a healthy environment, as a fundamental right, restrictions on locus standi, deficiencies in the EIA process and controversial statutory provisions negatively impacts on the environmental litigation process. On the other hand, inaccessibility to environmental justice process, the lack of awareness, political influence on the decision-making process, performance deficiency in enforcement agencies are the highlighted practical obstructions for achieving the task of explicating the sustainable development. Therefore, in order to eliminate the aforesaid gaps and shortcomings in the existing framework, importantly, the creative role of the judiciary via strengthening the public interest litigations, public trust doctrine, social justice approach and purposive approach in statutory interpretation is highly appreciated in achieving the aspirations of sustainable development to vindicate the environmental justice in national level. The main objective of this research is to examine the role of the judiciary in promoting the principle of sustainable development in Sri Lanka, in the light of the judicial activism in selected South Asian countries: namely, India, Pakistan and Bangladesh. This is a qualitative research, mainly carried out by the reference of secondary data.
\end{abstract}

Keywords: Sustainable development, Judiciary role, Public interest litigation 